\title{
CHARACTERISTICS OF RELATIVE DEPRIVATION OF DISADVANTAGED CHILDREN IN SCHOOL SETTING
}

\author{
Euis Nurhidayati, Sunaryo Kartadinata, M. Solehuddin, Syamsu Yusuf LN \\ *Correspondent Author
}

Euis Nurhidayati

Universitas Islam As-Syafi'iyah

Jalan Jatiwaringin Raya Nomor 12 , Jaticempaka, Pondok Gede, Bekasi, Jawa Barat, Indonesia

Email: 1978rinaya@gmail.com

\section{Sunayo Kartadinata}

Universitas Pendidikan Indonesia

Jalan Dr. Setiabudi Nomor 229, Isola,

Sukasari, Kota Bandung, Jawa Barat, Indonesia

Email: sunaryo.kartadinata@upi.edu

\section{Solehuddin}

Universitas Pendidikan Indonesia

Jalan Dr. Setiabudi Nomor 229, Isola,

Sukasari, Kota Bandung, Jawa Barat, Indonesia

Email: m.solehuddin@upi.edu

\section{Syamsu Yusuf LN}

Universitas Pendidikan Indonesia

Jalan Dr. Setiabudi Nomor 229, Isola,

Sukasari, Kota Bandung, Jawa Barat Indonesia

Email: syamsu.yusuf@upi.edu

\begin{abstract}
Relative deficiencies develop in two types of society: poor (deprived) and disadvantaged (unfortunate), little research for this arrangement has been conducted in the field of education. This will discuss the relative deprivation character of underprivileged children in the realm of education. This research uses a descriptive method. The descriptive survey was used to describe the relative character of deprivation among underprivileged children at school, knowing the differences between boys and girls. The subjects in this study were grade 5 and grade 6 elementary school students in the Bekasi area with a total of 77 students: 37 boys and 40 girls. The instrument used in this study is an instrument that has been tested by experts, validity and reliability. It uses a relative deprivation scale for disadvantaged children. The data were analyzed descriptively by describing the minimum and maximum scores of each item, thus showing strength of each characteristic. In addition, the frequency score also described to highlight differences in the relative characteristics of deprivation among male and female students. The results explained that the participants had a very strong deprivation character, males were more dominant than females. The strongest characters reflected their lesser curiosity about things, but the girls exhibit better score related to rule obedience. The results of this study could be used as a reference to treat students' relative deficiencies through guidance and counseling services.
\end{abstract}

Keywords: Relative Deprivation, Disadvantage children, Characteristics.

\section{INTRODUCTION}

The economic disparity in society may lead to various effect. The fact shows that the existing economic gap leads to social deprivation, which is generally described as a perception that one is worse off relative to those with whom one compares oneself (Flouri, et al., 2010; Liu, et al., 2019; Theiner, 2010; Greitemeyer \& Sagioglou, 2016). One's unfavorable experience could be worsened when he/she compares it with others in beter condition.

Social deprivation is characterized by four situations. First, the absence of social engagement in a society life; social engagement is a dynamic interaction in a warm, friendly society. Second, faded social cohesion, occuring when people do not have any more reason to stick together. Third, social detachment, occuring when each 
member of society has severe themselves from collective ties (association) within the group, hence, there are no direct relation within the group (Halevy, et al., 2010).

The findings on this book and some research output on social deprivation within social psychology acknowledge as relative deprivation. In short, relative deprivation could be described as a psychological condition that occurs due to unfulfilled hope from series of events (Yuan \& Wu, 2010; Chistian \& Ellis, 2011; Agbiboa, 2013). Crosby (Balsa, et al., 2014; Pettigrew, 2015) found five conceptually different theories on relative deprivation. The first description of relative deprivation comes from Aberle (Hyll \& Schneider, 2014) who defines relative deprivation as a gap between legitimate expectation and relation. This definition raises a debate especially on understanding legitimate expectation. Legitimate expectation definition varies from reference group and common man, some scholars even define it as past expectation. In more detail, Davis differentiates reference group as in- group and out-group. It is further explained that relative deprivation happens when one compares the situation with the other member of the within a group. Meanwhile, when one compares the situation with the outside the group, it is called social inferiority (Smith \& Huo, 2014). Both relative deprivation and social inferiority occurs when one's condition is worse than the comparative within the in group, then gratification exists, meanwhile when the comparative is outside the group then the social superiority exists (Ravallion \& Lokshin, 2010).

Second, Runciman argues that relative deprivation exists when an individual: (1) doesn't have $X,(2)$ knows that other people have $X,(3)$ wants to have $X$, and (4) feels he/she deserves to have $X$. According to Runciman, there are two types of deprivation, egoistical deprivation and fraternal deprivation. Egoistical deprivation happens when someone feels his/her condition is worse compared to others in his/her group. Meanwhile, fraternal deprivation happens when someone judges the situation of his/her group is worse than the other group. There is possibility someone feels both of this deprivation, hence, she/he experiences doubly deprived.

Third, Ted Robert Gurr defines relative deprivation as discrepancy between ought and is. He further elaborates that there are three types of deprivation. First, decremental deprivation that happens when the group expectation value does not change but the group capabilities decrease. Second, aspirational deprivation that raises when group capabilities remains stagnant but the expectation increase. Third, progressive deprivation happens when both of the element's shifts, capabilities decrease and expectation increase. Gur's relative deprivation model is more dynamic more than others' model

Fourth, according to Robin Williams discrepancy happens when there are gaps between what someone has and what he/she desires. Nevertheless, William differentiates between disappointments due to unfulfilled desire, and not wants. Here Williams also includes the importance of social comparison that triggers deprivation. Therefore, he gives social protest as the most apparent form of deprivation.

Fifth, Faye Crosby equalizes deprivation with resentment, sense of grievance and anger as its specific form. Specifically, Crosby emphasizes her study on egoistical deprivation as what has been proposed by Runciman. According to Crosby, egoistical deprivation on $X$ occurs when all five conditions are fulfilled: (1) the person who doesn't have $X$ desires $X,(2)$ that person see that other person has $X ;(3)$ deserving of $X$; (4) she/he feels deserve to have $X$; and (5) she/he doesn't feel guilty on things that made him/her fail to have $X$. The feeling of deprivation will amplify when the failure experience to have $X$, in the past, has caused a great lost feeling. In addition, the more people have $X$, the higher the social demand for him/her to have $X$, and the more amplified the deprived feeling. An interesting note on Crosby's views is that the emphasis that deprivation does not necessarily have negative consequences. This is different from 


\section{6 |PSIKOPEDAGOGIA}

JURNAL BIMBINGAN DAN KONSELING

Vol.9, No.1, June 2020

majority of scholars who generally agree that deprivation has negative consequences and trigger destructive actions (Becker, 2012; Smith \& Pettigrew, 2015).

Another relative deprivation theory was proposed by Stouffer. It emphasizes individual and group experience on deprived and disadvantaged conditions (Grant, et al., 2015). Children who grow up in deprived environment are later called disadvantage children. Disadvantage children (Edwards, 1974) are considered as children who did not prepared education as most of the middleclass children had. These children are usually less suitable with the settle school environment due to their lack of ability in communication, their parents only speak in simple/ verbal language (Wong, et al., 2015). Their positive sides are that they can get easily comfortable with new people, more responsive in socialization compared to the children with middle class background. Their parents put more emphasis on their behavior than their academic achievement.

Socially disadvantage children are those who grow up in various cultures or outside the middle class culture. The main characteristics of these children are poverty, and most of them live in the slum parts of the rural and urban area. The middle class considers education and raising their children as important things. They use policy, special opportunity, freedom and responsibility in assisting to raise each child. This principle is very different with socially disadvantage children, where they consider education as it is just to support their basic needs in life, such as counting and reading (Menchini \& Redmond, 2009).

Based on the explanation above, it is clear that social deprivation, mentioned in psychology as relative deprivation, is a condition where one is in deprived and disadvantage situation. The present research aimed to highlight those two issues i.e., deprivation and disadvantage, specifically specified on children within the school setting. The purpose of this study was to describe the relative deprivation characteristics of underprivileged children in primary schools and to determine the differences in the relative deprivation characteristics betwen male and female students. The results of this study can be used to develop students' relative deficiencies through guidance and counseling services.

\section{METHODOLOGY}

This descriptive survey study explore the characteristics of students who are less fortunate in an environment that is considered relatively less strong students, such as the waste-picker community. The survey was conducted using relative deprivation scale instruments that had previously been tested for validity and reliability. Participants in this study were students in grades $\mathrm{V}$ and $\mathrm{VI}$ of an elementary school in Bekasi. The total participants in this study were 77 students, 37 male and 40 females. This school was chosen as the location of the study because it had inadequate characteristics as the purpose of this study. This school is located in TPS Terpadu Bekasi, in an environment surrounded by garbage, and most of their parents are waste-pciker, $21 \%$ of the students even help their parents picking waste after school hours everyday. The data obtained in this study were analyzed descriptively by describing minimum and maximum score of each item to highlight the strength of each characteristic. The frequency score was also used to describe the differences in the relative characteristics of deprivation among male and female students.

\section{RESULT AND DISCUSSION}

As displayed in the following table, average score of social deprivation of these 77 students is 67.03 , with the standard deviation of 10.902 , the total score for all students is 5161 , with the minimum score of 47 and maximum score of 93 . Wide standard deviation (more than $30 \%$ of mean) indicates great variation, or a wide gap between the lowest and the highest score. 
Based on Table 1 the descriptive calculation above, it is found that the total score of social deprivation was 67.03 or $54.05 \%$ of the total ideal of each item that is 124. Hence, it is concluded that the impact of the deprivation on students of Dinamika Indonesia Elementary School is classified as high impact.

Table 1.

Descriptive Statistics

\begin{tabular}{llllllr}
\hline & N & Min & Max & Sum & Mean & $\begin{array}{r}\text { Std. } \\
\text { Dev }\end{array}$ \\
\hline $\begin{array}{l}\text { Deprivasi } \\
\text { Sosial }\end{array}$ & 77 & 47 & 93 & 5161 & 67.03 & $\begin{array}{r}10.90 \\
2\end{array}$ \\
$\begin{array}{l}\text { Valid N } \\
\text { (listwise) }\end{array}$ & 77 & & & & & \\
\hline
\end{tabular}
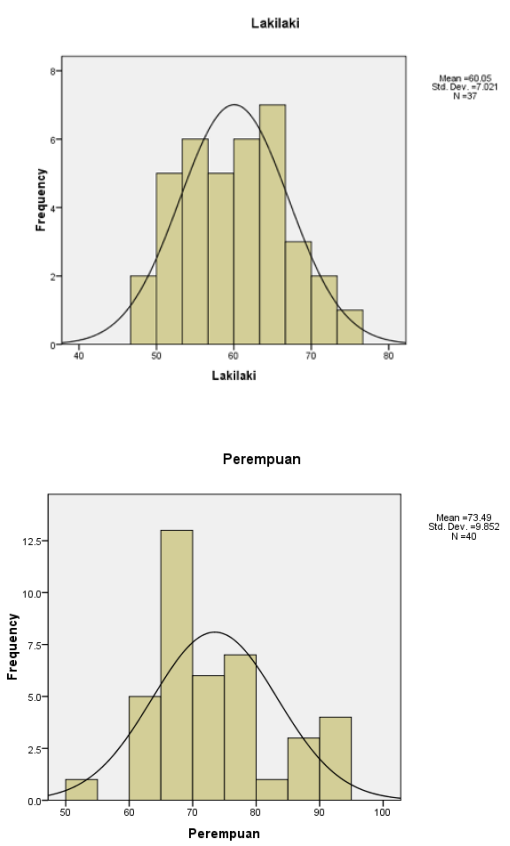

Figure 1.

Frequency of relative deprivation score and female students

The mean score of male students was 60.05 with standard deviation of 7.021 While those of female students were 73.49 with standard deviation of 9.854 in. Figure 2 indicates that the impact of deprivation on male students are higher than on the female students. It is stated that the lower the deprivation score, the higher the impact of deprivation, and vice versa (McKearney \& $\mathrm{Ng}, 2014$ ).

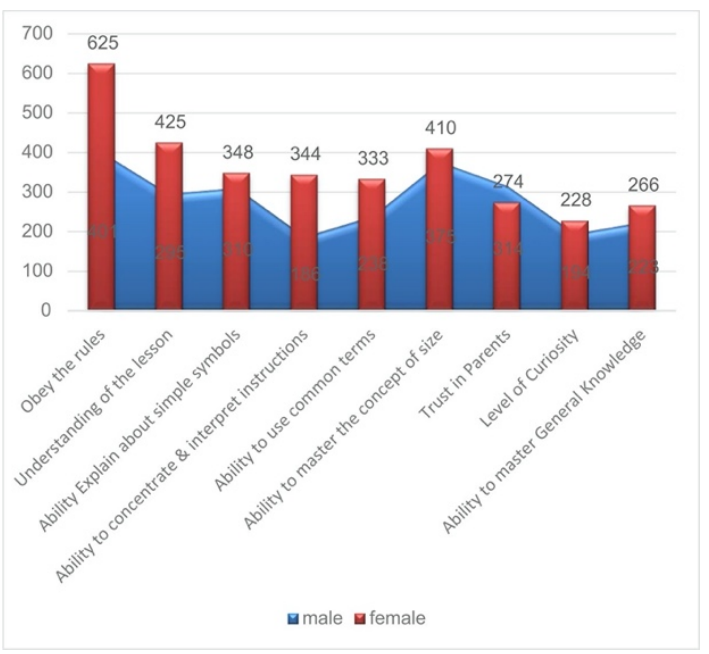

Figure 2.

Charahcteristics of Relative Deprivation on Disadvantage Children With Education Setting

As displayed in the Figure 2, all the characteristic of male students are lower than the female students, meaning that the deprivation characteristics on male students are stronger than on the female students. The strongest deprivation characteristics on male students are: 1) lack of curiosity, 2) lack of ability to describe symbols, 3) lack of trust in parents, and 4) lack of ability in mastering general knowledge.

On the other hand the strongest deprivation characteristics on female students are: 1) lack of curiosity, 2) lack of trust in parents, and 3) lack of ability in mastering general knowledge. The lowest deprivation characteristics on female students was obedience toward regulation with the score of 625 , which means that female students are able to obey many regulation in school.

Based on the total result, out of the nine characteristics, eight characteristics gained low scores and the average maximum score was 740 , and the average score obtained by students was only 350 . This score indicates that can be concluded that the relative deprivation characteristics on disadvantage children (students of Dinamika Indonesia 


\title{
58 |PSIKOPEDAGOGIA
}

\author{
JURNAL BIMBINGAN DAN KONSELING
}

Vol.9, No.1, June 2020

elementary school) within the education setting is categorized as strong.

Lentillon, et al. (2006) conducted a study entitled Injustice in physical education: gender and the perception of deprivation in grades and teacher support. Respondents of this research were middle school students in France that consist of 1620 students from 19 different schools (Ten junior high school and 9 senior high schools). The school samples were selected based on the variation of the students' social background. The average age of students (908 female students, and 708 male students) are 15.12 years old. The measurement in this research used the instrument that can describe the level of perception of injustice (deprivation) with focus on two domains, "instrumental perception of deprivation" to test the class, and "relational perception of deprivation" to test the teacher support. The result showed that the lack of acceptance in class compared to the expectation, however, from the teacher side, the teachers have given support more than expected, so there are low correlation between the perception of injustice in grades and teacher support with the score of $r=0.09, t 1508=3.48, p<0.01$.

In Lentillon et al's (2006) research, deprivation is defined as students perception of injustice in grades and teachers support, these deprivation was not based on the family background and their environment or disadvantage, it is different from the data collected in the present study, which was taken from school that is uniquely located in deprived environment, i.e., waste-picker environment. The present study is similar to Lentillon et al's (2006) in the way that this research also indirectly described the characteristics of students deprivation in grades, by referring to the nine indicators above.

In Fox, Almas, Degnan, Nelson \& Zaenah (2011) research entitled the effects of severe psychosocial deprivation and foster care intervention on cognitive development at 8 years of age: findings from Bucharest Early Intervention Project. The main report describes the data from 8-years old children.
136 students were tested using the WISC IV. The result revealed the advantage of intervention program, although the children both in control group and intervention group are no longer stay in their original placement. The IQ score was very prevalent for children that belong to the family in the intervention group. The conclusion of this data was a recommendation to continue the early intervention and the negative effects of severe psychosocial deprivation on development of IQ scores across early childhood.

The intervention program has succeeded to increase the IQ score of the children. And the negative effect of psycho-social deprivation in IQ score can be minimized. This research gives great contribution to deprivation research in educational setting. That intervention program can be done in helping children to increase their potential and minimize the negative impact of deprivation.

In this research, it is reported that several characteristics of relative deprivation on disadvantage children related to the lack of general knowledge $(I Q)$ that categorized as strong characteristics with low score, such as ability to master general knowledge and ability to describe the simple symbols.

In the study conducted by Hirsch (2007) entitled Experience of poverty and educational disadvantage, there were eight key points in his research, namely: 1) Low income is the main predictor of one's poor education performance, 2) White children in poverty is within low education achievement even heading to the under-achieve. Male children have low result than female children, especially those with Bangladeshi, Pakistani, and black African background, 3) Only $14 \%$ of individuals study in qualified schools. Many variations due to other factors, 4) Children with different background have contrast experience in school. It is harder for disadvantage children to control their learning (Katchergin, 2012). They often reluctant to receive the learning. This influences their attitude development to make education as their main tools to help them 
out of their situation, 5) Children from all background love school, but those with lack of funding feel anxious and less confident in school, 6) Extracurricular activities can help build self-confidence. More advantageous children have experience in managing and supervising their extracurricular activities,7) Many children hate school due to mistreatment factor (e.g, racial discrimination experience), 8) These factors are the core of the social gap in education world; however, no solution is proposed by government to resolve these problems.

The above description is also apparent in the environment where the present research was conducted, in which there were $21 \%$ children who helped their parents to pick waste, if their job target increase, children are usually asked to help more even though during the school hour. This value indirectly makes students think that education is not a priority. On the other hand, related to discrimination, there is hardly any discrimination because they come from homogenous community, where the majority of their parents were waste-picker. This was not reflected in this research, but in the follow up research that would conduct the survey on relative deprivation in disadvantage children through educational and jobs background of their parents. And all the nine characteristics of deprivation characteristics can further be explored. It can even be developed into a program to heal children who are affected by deprivation.

The research on deprivation in educational setting are scarce, the literature on this subject was not developed progressively. In Indonesia, studies on deprivation is discussed under human resource field, and only few of them are relevant with education sector. The present study is an initial step to help unveil relative deprivation in various educational issues in order to provide better treatment for children who experience deprivation and for Indonesian education in general.

The characteristics in this research describe the ability, deprived attitude, and behaviors, However the data were still modest. The root cause that determines the strength of the characteristic had not been confirmed due to limited reference related to deprivation especially in educational setting. Accordingly, further research are strongly recommended.

This research is conducted as an initial step to reveal relative deprivation issues in educational setting. Future studies are still needed to describe the deprivation in educational setting. Moreover, such studies may be useful to establish a relative deprivation theory in Indonesian context.

\section{CONCLUSION}

This research describes that relative deprivation characteristics on students of the elementary school is categorized as strong, and male students have stronger relative deprivation characteristic than female students. The strongest characteristics in both male and female students are lack ofl of curiosity. It was also found that female students exhibited better obedience than male students did.

\section{REFERENCES}

Agbiboa, D. E. (2013). Why Boko Haram exists: The relative deprivation perspective. African Conflict and Peacebuilding Review, 3(1), 144-157.

Balsa I. Ana, French T. Michael \& Regan L. Tracy, (2014), Relative Deprivation and Risky Behaviors, The Journal of Human Resources.

Becker, J. C. (2012). The system-stabilizing role of identity management strategies: Social creativity can undermine collective action for social change. Journal of Personality and Social Psychology, 103(4), 647.

Christian, M. S., \& Ellis, A. P. (2011). Examining the effects of sleep deprivation on workplace deviance: $\mathrm{A}$ self-regulatory perspective. Academy of Management Journal, 54(5), 913934.

Edwards, J. R.. (1974). Characteristics of Disadvantaged Children. The Irish Journal of Education / Iris Eireannach an Oideachais, 8(1), 49-61. 


\section{0 |PSIKOPEDAGOGIA}

JURNAL BIMBINGAN DAN KONSELING

Vol.9, No.1, June 2020

Flouri, E., Mavroveli, S., \& Tzavidis, N. (2010). Modeling risks: Effects of area deprivation, family socio-economic disadvantage and adverse life events on young children's psychopathology. Social Psychiatry and Psychiatric Epidemiology, 45(6), 611.

Fox, N. A., Almas, A. N., Degnan, K. A., Nelson, C. A., \& Zeanah, C. H. (2011). The effects of severe psychosocial deprivation and foster care intervention on cognitive development at 8 years of age: Findings from the bucharest early intervention project. Journal of Child Psychology and Psychiatry, 52(9), 919-928.

Grant, P. R., Abrams, D., Robertson, D. W., \& Garay, J. (2015). Predicting protests by disadvantaged skilled immigrants: A test of an integrated social identity, relative deprivation, collective efficacy (SIRDE) model. Social Justice Research, 28(1), 76-101.

Greitemeyer, T., \& Sagioglou, C. (2016).

Subjective socioeconomic status causes aggression: A test of the theory of social deprivation. Journal of personality and social psychology, 111(2), 178.

Halevy, N., Chou, E. Y., Cohen, T. R., \& Bornstein, G. (2010). Relative deprivation and intergroup competition. Group Processes \& Intergroup Relations, 13(6), 685-700.

Hirsch, Donald. (2007). Experience of Pooverty and Educational Disadvantage, Joseph Rowntree Foundation.

Hyll, W., \& Schneider, L. (2014). Relative deprivation and migration preferences. Economics Letters, 122(2), 334-337.

Katchergin, O. (2012). Between negative stigma (cultural deprivation) and positive stigma (learning disability): The historical development of two special education tracks. Culture, Medicine, and Psychiatry, 36(4), 679711.
Lentillon, V., Cogérino, G., \& Kaestner, M. (2006). Injustice in physical education: Gender and the perception of deprivation in grades and teacher support. Social Psychology of Education, 9(3), 321-339.

Liu, Y., Zhang, F., Liu, Y., Li, Z., \& Wu, F. (2019). Economic disadvantages and migrants' subjective well-being in China: The mediating effects of relative deprivation and neighbourhood deprivation. Population, Space and Place, 25(2), e2173.

McKearney, A., \& Ng, E. S. (2014). Relative deprivation, self-interest and social justice: why I do research on inequality. Equality, Diversity and Inclusion: An International Journal.

Menchini, L., \& Redmond, G. (2009). Poverty and deprivation among children in eastern europe and central asia.International Journal of Social Welfare, 18(3), 225-236.

Pettigrew, T. F. (2015). Samuel Stouffer and relative deprivation. Social Psychology Quarterly, 78(1), 7-24.

Ravallion, M., \& Lokshin, M. (2010). Who cares about relative deprivation? Journal of Economic Behavior and Organization, 73(2), 171185.

Smith, H. J., \& Huo, Y. J. (2014). Relative deprivation: How subjective experiences of inequality influence social behavior and health. Policy Insights from the Behavioral and Brain Sciences, 1(1), 231-238.

Smith, H. J., \& Pettigrew, T. F. (2015). Advances in relative deprivation theory and research. Social Justice Research,28(1), 1-6.

Theiner, G., Allen, C., \& Goldstone, R. L. (2010). Recognizing group cognition. Cognitive Systems Research, 11(4), 378-395.

Wong, Y., Wang, T., \& Xu, Y. (2015). Poverty and quality of life of chinese children: From the perspective of deprivation. International Journal of Social Welfare, 24(3), 236-247. 
Yuan, Y., \& WU, F. (2010). The Evaluation of Urban Social Space from the Perspective of Deprivation Theory [J]. In Urban Planning Forum, 1, 71-77. 